Discussion Paper No. 515

PRICE DISCLOSURE, MARGINAL ABATEMENT COST INFORMATION AND MARKET POWER

IN A BILATERAL GHG EMISSIONS TRADING EXPERIMENT

\author{
Yoichi Hizen \\ and \\ Tatsuyoshi Saijo
}

\author{
August 2000 \\ The Institute of Social and Economic Research \\ Osaka University \\ 6-1 Mihogaoka, Ibaraki, Osaka 567-0047, Japan
}




\title{
Price Disclosure, Marginal Abatement Cost Information and Market Power in a Bilateral GHG Emissions Trading Experiment ${ }^{\#}$
}

\author{
Yoichi Hizen*1, *2 \\ and \\ Tatsuyoshi Saijo**1, **2
}

August, 2000

\# This research was partially supported by CREST (Core Research for Evolutional Science and Technology) of the Japan Science and Technology Corporation (JST). We also thank Professor James C. Cox and participants of the CREST workshop for helpful comments and discussions, and Dr. Yasuko Kawashima of the National Institute for Environmental Studies in Japan for providing marginal abatement cost information.

*1 Graduate School of Economics, Osaka University, Toyonaka, Osaka 560-0043, Japan

*2 Research Fellow of the Japan Society for the Promotion of Science

**1 Institute of Social and Economic Research, Osaka University, Ibaraki, Osaka 567-0047, Japan

**2 CREST, Japan Science and Technology Corporation, 3-12-40 Hiroo, Shibuya, Tokyo 150-0012, Japan 


\begin{abstract}
We conducted an experiment to examine the performance of the bilateral trading institution in GHG emissions trading. First, we found that the efficiency of bilateral trading is quite high, regardless of the disclosure or closure of contracted price and/or marginal abatement cost curve information. Second, marginal abatement costs are equalized over time. Third, on the other hand, contracted prices did not converge to the competitive price over time. Fourth, subjects who had market power did not use it.

Journal of Economic Literature Classification Numbers: C92, Q31, Q38
\end{abstract}

\title{
Correspondent:
}

Tatsuyoshi Saijo

Institute of Social and Economic Research

Osaka University

Ibaraki, Osaka 567-0047

Japan

Phone 01181-6 (country \& area codes)

6879-8571 (office)/ 6878-2766 (fax)

E-mail: saijo@iser.osaka-u.ac.jp 


\section{Introduction}

To prevent the global warming, the discussion on how to control the total amount of greenhouse gases (GHG's) has started among countries in the late of 1980's. At the third session of the Conference of the Parties (COP3) to the United Nations Framework Convention on Climate Change (UNFCCC) at Kyoto in December, 1997, the Kyoto Protocol was adopted, which was the first agreement on the quantified GHG emission limitation. It assigns each Annex B country the quantity she should comply with, and calls for these countries to reduce their overall emissions by at least five percent below 1990 levels in the commitment period 2008 to 2012. To assist the countries in achieving compliance, the Protocol authorizes three major mechanisms, that is, emissions trading, joint implementation and the Clean Development Mechanism. The details of mechanisms, however, remained to be elaborated. Designing these mechanisms is an urgent task since they should start working by 2008 at the latest. Among them, this paper focuses on designing desirable institutions for GHG emissions trading through the use of experimental economics. 1

Although we know "roughly" that introducing a market for GHG emissions achieves the lowest cost to reduce them, we do not know how the emissions should be traded in the market. As a first step toward designing the GHG emissions trading institution, this paper deals with bilateral trading. There are two main backgrounds to start with bilateral trading. First, the participants in the GHG emissions trading are countries. Thus, bilateral negotiations between the government officials of two countries can be the major style of trading. Second, we already have an example of bilateral trading used as an emissions trading institution. In the U.S.A., the acid-rain control program in

\footnotetext{
${ }^{1}$ For recent experimental results in emissions trading, see Muller and Mestelman (1998) and Godby, Mestelman and Muller (1998).
} 
the Clean Air Act Amendments of 1990 introduced tradable emission allowances for sulfur dioxide, and most of the trades have been carried out through bilateral trading. This program attained the greater reduction of sulfur dioxide emissions than the assigned amount. However, we cannot conclude from this observation that bilateral trading works best as an emissions trading institution because there were other factors which might lead to this great reduction, for example, the permission for banking, the reduction of marginal abatement costs, and the combined use of annual auctions. We cannot compare the result of this program with the case of competitive equilibrium or the case of other institutions, without the firms' abatement cost information or the data from other institutions. Thus, the experiment on bilateral trading also provides a basis for evaluating sulfur dioxide allowance trading in the U.S.A.2

The bilateral trading examined in this paper has a special feature, which we call the dual role property of a trader. That is, each participant in the institution can be a buyer and a seller depending on the allowance price. This is a natural property of real emissions trading, but each subject is assigned to be either a buyer or a seller in most previous experiments in emissions trading. Recently, Bohm (1997) employed this property, and reported a bilateral trading experiment among four teams consisting of experienced public officials or experts appointed by the Energy Ministries. Each team represented one of the four Nordic countries, and had some information on the marginal abatement cost curves of all teams. 1 The asks and bids were exchanged by fax without revealing this information to other teams. It took four days to complete this experiment. The resulting

\footnotetext{
2 Some evaluation of sulfur dioxide emissions trading has just started. See, for example, Schmalensee et. al. (1998) and Stavins (1998).

3 Bohm distinguished two concepts of marginal abatement cost curves. Technical marginal cost curves are based upon scientific knowledge. He assumed that each team knew the others' technical cost curves very well, but did not know social marginal abatement cost curves. Social abatement costs include considerations of realworld political constraints concerning employment and distribution effects. Cost curves used in his experiment were social ones. In our experiment, these two concepts coincide.
} 
prices were very close to the competitive equilibrium price and its efficiency was $97 \%$, which is surprisingly high.

Following Bohm's important experiment, we designed a bilateral trading experiment with two controls: (i) disclosure or closure of contracted prices, and (ii) disclosure or closure of marginal abatement cost curves. Thus, there are four different treatments. In this way, we can understand which information treatment would be effective for bilateral trading to work as a GHG emissions trading institution.

We conducted two sessions for each treatment. The first finding is that the efficiency of the eight sessions is very high, regardless of information closure or disclosure. That is, disclosure of contracted prices and/or marginal abatement cost information does not improve efficiency. It was more than $99 \%$ in 6 sessions, and $98 \%$ and $92 \%$ in the remaining sessions. This finding contrasts strikingly with the widely accepted view on bilateral trading, that is, (i) it would be inefficient in the sense that some dissatisfied traders could not be eliminated due to mismatching, and (ii) the revelation of contracted prices would improve its efficiency. \$Second, marginal abatement costs are equalized in most of the sessions except for the $92 \%$ efficiency session. Third, the contracted prices did not converge to the competitive equilibrium price. This observation is different from Bohm's. Fourth, subjects who could exercise market power did not use that power. In each session, we had six subjects who were supposed to represent Russia, Ukraine, U.S.A., Poland, EU, and Japan. In our setting, only the U.S.A. had market power, and the subjects who were assigned this role did not reduce their quantity demanded in order to lower the price.

\footnotetext{
4 These views are not based upon either economic theory or empirical evidence. Feldman (1973) shows that allocations through bilateral trading can attain Pareto efficiency in a finite number of steps.
} 
The paper is organized as follows. In the next section, we describe the experimental design in detail, and section 3 presents the results. In section 4 , we discuss why efficiency is so high and consider the implication of disclosure of contracted prices. Section 5 discusses the future agenda.

\section{Experimental Design}

The experiment has two controls: (i) disclosure or closure of contracted prices, and (ii) disclosure or closure of marginal abatement cost curves. Therefore, there are four treatments. Repeating the same treatment twice yields eight sessions. In what follows, "O" represents "disclosure" and "X" represents "closure". For example, "OX2" indicates session 2 in the price disclosure, marginal cost curve closure treatment. That is, the first digit indicates price information, the second digit marginal cost curve information, and the last the session number.

We recruited at least six students for each session by campus-wide advertisement at Osaka University during October, 1998. These students were told that there would be an opportunity to earn money in a research experiment. None of them had prior experience in a bilateral trading experiment. It took approximately 160 minutes for each session. The mean payoff per subject was $\$ 31.25$ ( $\$ 1=115$ yen). The maximum payoff was $\$ 66.09$, and the minimum payoff was $\$ 17.39$.

Figure 1 is around here

Let us describe an "OO" session. Eight subjects were seated at desks in a relatively large room and listened to a tape-recorded voice giving instructions. This instruction part took about 45 minutes. In this part, each subject received a sample graph (see Figure 1). 
The upper half is a sample marginal abatement cost curve. Each subject was told that the initial position is at $0 .{ }^{5}$ If the subject moves to the right, she buys the allowance and earns benefits, and if she moves to the left, she sells the allowance and obtains a profit. All possible situations were depicted in the lower half of Figure 1. After receiving instructions on how to transact with other subjects, all subjects took an examination to check their understanding of the instructions. The best six subjects continued the experiment, and the rest were asked to leave the room with $\$ 13$. Then each subject was assigned an identification number from 1 to 6 and, at the same time, each subject received her own marginal abatement cost curve. In the "OO" session, each subject received Figure 2 with all six abatement cost curves, and had fifteen minutes to examine it (i.e., marginal abatement cost curve disclosure). ${ }^{\square}$ Then bilateral trading started. Since every subject had a tag with an identification number, subjects could identify other subjects' marginal abatement cost curves. Every subject could move around the room freely to find a subject with whom to transact. During negotiations, subjects were not allowed to talk. Only numbers (price and quantity), and "yes" and "no" symbols on their negotiation sheets, were exchanged in order to avoid information leakage. Once a pair reached an agreement, they reported the price and quantity to an experimenter, who announced these numbers on the blackboard (i.e., contracted price disclosure). The maximum time for negotiations was 60 minutes, and subjects could end their negotiations early if all subjects agreed to it. The full 60 minutes was used in all sessions except "XO2." In this session, subjects quit at 58:30.

Figure 2 is around here

\footnotetext{
${ }^{5}$ We implicitly presume that position 0 is the position where each country attains the goal required by the Kyoto Protocol. In other words, our experimental setting asks what kind of trading should be done in order to achieve that goal. That is, we did not address the non-compliance issue.

${ }^{6}$ The number of subjects who actually participated in bilateral trading was 6 . Sessions where 8 subjects participated at the outset were "OO1", "OO2", and "XO2", sessions with 7 subjects were "OX2", "XX1", and "XX2", and sessions with 6 subjects were "OX1" and "XO1".

${ }^{7}$ Since information on the marginal abatement cost curves around 2010 is hard to obtain, we draw these curves based upon some information provided by Dr. Kawashima.
} 
During the experiment, we did not use any country names or the term "emissions trading." That is, subjects faced a situation where trading of an abstract commodity was conducted with an abstract price.

\section{Experimental Results}

\subsection{Efficiency of Bilateral Trading}

Let us define the efficiency of bilateral trading as follows:

Sum of benefit and profit of each subject

\section{Sum of benefit and profit at market equilibrium}

In our design, the competitive equilibrium price ranges from 118 to 120 . We regard 119, which is the midpoint between 118 and 120, as the competitive equilibrium price. At this price, the total amount of benefit and profit (that is, the maximum amount that these six subjects can enjoy) is 6990 . In Table 1 , the top row indicates the name of the sessions, the left column shows the I.D. numbers of subjects, and the numbers in parentheses are their benefits or profits at the competitive equilibrium price. In each cell, the upper figure is the actual benefit or profit that the subject earned, and the lower figure is the efficiency of this subject. For example, the 0.732 figure for subject 1 in the "OO2" session is the ratio between 1870 and 2555, which we call individual efficiency. 


\begin{tabular}{|c|r|r|r|r|r|r|r|r|}
\hline & OO1 & OO2 & OX1 & OX2 & XO1 & XO2 & XX1 & XX2 \\
Subject No. & & & & & & & & \\
\hline 1(2555) & 1420 & 1870 & 960 & 1710 & 1510 & 1100 & 1460 & 1600 \\
(Russia) & 0.556 & 0.732 & 0.376 & 0.669 & 0.591 & 0.431 & 0.571 & 0.626 \\
\hline $2(1290)$ & 1140 & 914 & 360 & 1665 & 1320 & 940 & 1536 & 2370 \\
(Ukraine) & 0.884 & 0.709 & 0.279 & 1.291 & 1.023 & 0.729 & 1.191 & 1.837 \\
\hline $3(610)$ & 685 & 683 & 2060 & 372 & 1846 & 615 & 583 & 550 \\
(U.S.A.) & 1.123 & 1.120 & 3.377 & 0.610 & 3.026 & 1.008 & 0.956 & 0.902 \\
\hline $4(390)$ & 520 & 570 & 850 & 530 & 500 & 555 & 910 & 500 \\
(Poland) & 1.333 & 1.462 & 2.179 & 1.359 & 1.282 & 1.423 & 2.333 & 1.282 \\
\hline $5(620)$ & 800 & 1105 & 1300 & 755 & -150 & 1080 & 81 & 150 \\
(EU) & 1.290 & 1.782 & 2.097 & 1.218 & -0.242 & 1.742 & 0.131 & 0.242 \\
\hline $6(1525)$ & 2425 & 1800 & 1450 & 1844 & 1400 & 2700 & 2390 & 1800 \\
(Japan) & 1.590 & 1.180 & 0.951 & 1.209 & 0.918 & 1.770 & 1.567 & 1.180 \\
\hline Sum(6990) & 6990 & 6942 & 6980 & 6876 & 6426 & 6990 & 6960 & 6970 \\
& 1 & 0.993 & 0.999 & 0.984 & 0.919 & 1 & 0.996 & 0.997 \\
\hline
\end{tabular}

Table 1. Efficiency of Bilateral Trading

As Table 1 shows, the efficiency of each session is quite high, except for "XO1." The reason for the low efficiency level in this session is that subject 5 traded with other subjects even though she suffered a loss. Individual efficiencies are quite different even for the same subject number. Statistical tests show that Russia consistently earned a much lower profit than that of the competitive equilibrium and Poland earned a greater profit than that of the competitive equilibrium. The efficiency of the other countries is close to one. As we discuss later, the only country that had some market power was the U.S.A. We still do not understand why Russia and Poland deviated from the competitive equilibrium efficiency and why the U.S.A. did not use its market power.

Figure $2 \frac{1}{2}$ is around here

Figure $2 \frac{1}{2}$ shows efficiency changes over time. After sixteen minutes, the efficiency in all sessions except for session "XX2" was greater than $80 \%$, and it was more than $90 \%$ in 6 sessions of 8 after 25 minutes. Efficiency usually is monotonically increasing, but in session "OX2" efficiency moved up and down. This was due to the fact 
that one subject bought allowances at a loss, but sold it at a relatively high price. Summarizing these findings, we have:

Observation 1. (i) The efficiency of bilateral trading is almost one, regardless of closure or disclosure of price and marginal abatement cost information.

(ii) Russia's efficiency is low, Poland's efficiency is high, and the efficiency of the other countries is close to one.

(iii) The efficiency in 6 sessions of 8 was more than $90 \%$ after 25 minutes.

From this observation, high efficiency seems to be an intrinsic property of bilateral trading under the dual role property.

\subsection{Contracted Prices in Bilateral Trading}

Figures 3-1 and 3-2 show contracted prices and quantities over time. The green horizontal line in each small graph shows the competitive equilibrium price range of 118120. The left-hand side number of a square is the seller's subject number, the right-hand side number is the buyer's subject number, and the number under the square is the contracted quantity. If the variance of the last three contracted prices is significantly smaller than the variance of the first three prices, then we say that the contracted price sequence converges. We find the convergence of contracted prices in five of eight sessions, but no information disclosure effect is observed. Similarly, Figures 4-1 and 4-2 show bids and asks over time. A square denotes an ask, and a triangle a bid.

Figures 3-1, 3-2, 4-1, and 4-2 are around here 
Observation 2. (i) Contracted average prices in the "XX" sessions (closure of prices and closure of marginal abatement cost curves) roughly equal the competitive equilibrium price, but the variances of prices in the "XX" sessions are larger than those of the rest.

(ii) Average prices cannot be said to equal the competitive equilibrium price in sessions other than the "XX" sessions.

(iii) The average price of the last three contracts is not equal to the competitive equilibrium price in any session.

(iv) The convergence of contracted prices is found in five of eight sessions, but no information disclosure effect on convergence is observed.

By the nature of bilateral trading, the price contracted by a pair of subjects is determined by negotiation. Even though several other contracted prices have already been announced, a pair of subjects cannot reach an agreement if either of them rejects these prices. For this reason, the competitive equilibrium price cannot play the role of the standard of trade.

3.3 The Effect of Disclosure of Contracted Price and Marginal Abatement Cost Curve Information

The effect of disclosure of contracted prices can be calculated by comparing the "OO" and "XO" sessions, and the "OX" and "XX" sessions. Since the variances of contracted prices in sessions "OX1" and "OX2" cannot be said to be the same, we omitted these sessions from the comparison. Under this constraint, we compare the "OO" sessions with the "XO" sessions. No differences are observed among the variances of these sessions. 
For the same reason mentioned in the above paragraph, we compare the "XO" sessions with the "XX" sessions to measure the effect of disclosure of marginal abatement cost curve information. We find that the variance of contracted prices in the "XO" sessions is smaller than in the "XX" sessions. Summarizing these facts, we have:

Observation 3. (i) Assuming that each subject knows other subjects' marginal abatement cost curves well, the disclosure of contracted prices does not have any impact on the variance of contracted prices.

(ii) Under the closure of contracted prices, the disclosure of marginal abatement cost curves reduces the variance of contracted prices.

\subsection{Equalization of Marginal Abatement Costs over Time}

Behind efficiency, we can see how marginal abatement costs changed over time. Figures 5-1 and 5-2 show their change in each session. If a subject sells allowances and reaches the kink on the marginal cost curve, we choose the right-hand side cost figure, and if a subject buys allowances and reaches the kink on the marginal cost curve, we choose the left-hand side cost figure. Due to the step-function nature of our marginal abatement cost curve, we must be careful when evaluating marginal costs. For example, the marginal abatement cost of Russia in session "OO1" was 90 after 25 minutes. Checking the raw data, we find that Russia sold exactly 55 units of emissions allowance in 25 minutes. Therefore, if the subject wanted to sell one more unit, its marginal abatement cost would have been 120 (see Figure 2). Taking account of this fact, we have:

Observation 4. Except for the EU subject in session "XO1," the marginal abatement costs of all subjects approach the competitive equilibrium price, but the contracted prices do not. 


\subsection{Market Power Issue}

In order to understand how much market power a country has, we need an aggregate excess demand curve of all subjects regarding marginal abatement cost curves as the excess demand curves for emissions allowances. After careful examination, we find that the only country that has market power in our design is the U.S.A. Table 1 shows that the benefits of the U.S.A. were more than three times the benefit at the competitive equilibrium in two sessions of eight. A statistical test shows that the U.S.A. did not exercise market power in the experiment. Most probably, the subjects could not exploit the marginal abatement cost curve information to use such market power.

\section{Discussions}

Let us think about how high efficiency can be promoted by the dual role property, that is, each country can buy and sell the allowance depending on the price. Consider the following simple demand and supply curves with two sellers and two buyers. Each seller has just one unit of a good. On the other hand, each buyer wants to buy just one unit of the good. Apparently the competitive equilibrium price must be between 4 and 7 , and the social surplus becomes 8 . If buyers can only buy and sellers can only sell, a mismatch can easily occur. Consider a pair in which the buyer's value is 10 and the seller's cost is 7 . If they trade with each other, the surplus is 3 . Consider another pair in which the buyer's value is 4 and the seller's cost is 2 . The surplus of this pair is 2 and hence the sum of the surplus is 5 , which is less than 8 . After these trades, no mutually beneficial trade will occur. Now consider the case in which everyone can buy and sell. After these trades, the 
buyer whose value is 4 has one unit of the good and hence she can sell it. Since the seller whose cost is 7 does not have any good, he can buy it. If this pair trades with each other, they can enjoy 3 units of surplus, so that the total surplus becomes 8 . Actually, starting from any trading pair, we can find a path that leads to a Pareto efficient allocation.

\section{Price}

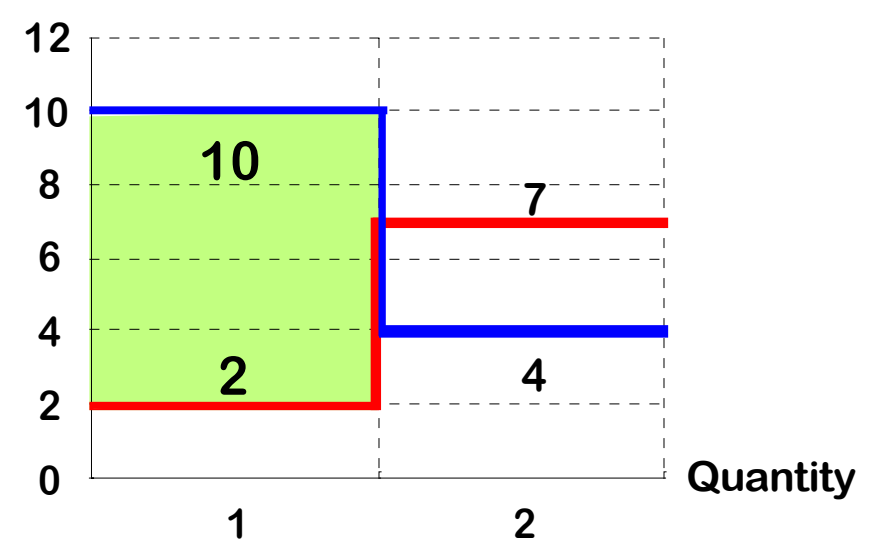

Figure 6. Efficiency of Bilateral Trading

The experiment did not show any significant effects of disclosure of contracted prices on the variance in bilateral trading. This does not necessarily imply that the closure of contracted prices is better than disclosure. First, if the disclosure or closure of contracted prices does not matter, there is no reason why they should be hidden. Although the experimental results did not show any significant difference, something unexpected might occur in future emissions trading. For this safety reason, transactions should be undertaken in public. Second, the transaction of GHG emissions allowances is not a truly private economic activity. As it would affect absolutely everyone, it should be done in public.

\section{Concluding Remarks}


In this experiment, it was found that, first, the efficiency of bilateral trading is quite high, regardless of the disclosure or closure of contracted prices and/or marginal abatement cost curve information. That is, high efficiency seems to be an intrinsic property of bilateral trading under the dual role property. Second, marginal abatement costs are equalized over time. Third, on the other hand, contracted prices did not converge to the competitive price over time. Fourth, subjects who had market power did not use it.

We used just six subjects in each session. If the number of participants increases, the number of possible matchings increases with the square order of the number of participants. That is, if there are many participants in bilateral trading, they cannot communicate well through matching. Therefore, the number of subjects is an open question to be explored.

Our experiment is a prelude to several more experiments that aim at designing the entire emissions trading institutions. In order to provide a solid basis for such a design, we plan to conduct the following: (1) Oral double auction experiment, (2) Banking experiment, (3) Non-compliance experiment, (4) Liability experiment and (5) Market power experiment. 


\section{REFERENCES}

Bohm, Peter, A Joint Implementation as Emission Quota Trade: An Experiment among Four Nordic Countries, Nord 1997:4 by Nordic Council of Ministers, June, 1997.

Feldman, Allan M., "Bilateral Trading, Processes, Pairwise Optimality, and Pareto Optimality," Review of Economic Studies 40(4), Oct. 1973, pp. 463-73.

Godby, Robert W., Stuart Mestelman, R. Andrew Muller, "Experimental Tests of Market Power in Emission Trading Markets," mimeo., September, 1998.

Muller, R. Andrew and Stuart Mestelman, "What Have We Learned From Emissions Trading Experiments?" Managerial and Decision Economics 19(4-5), June-August, 1998, pp. 225-238.

Stavins, Robert N., "What Can We Learn from the Grand Policy Experiment? Lessons from $\mathrm{SO}_{2}$ Allowance Trading," Journal of Economic Perspectives 12(3), Summer, 1998, pp. 69-88.

Schmalensee, Richard, Paul L. Joskow, A. Denny Ellerman, Juan Pablo Montero, and Elizabeth M. Bailey, "An Interim Evaluation of Sulfur Dioxide Emissions Trading," Journal of Economic Perspectives 12(3), Summer, 1998, pp. 53-68. 


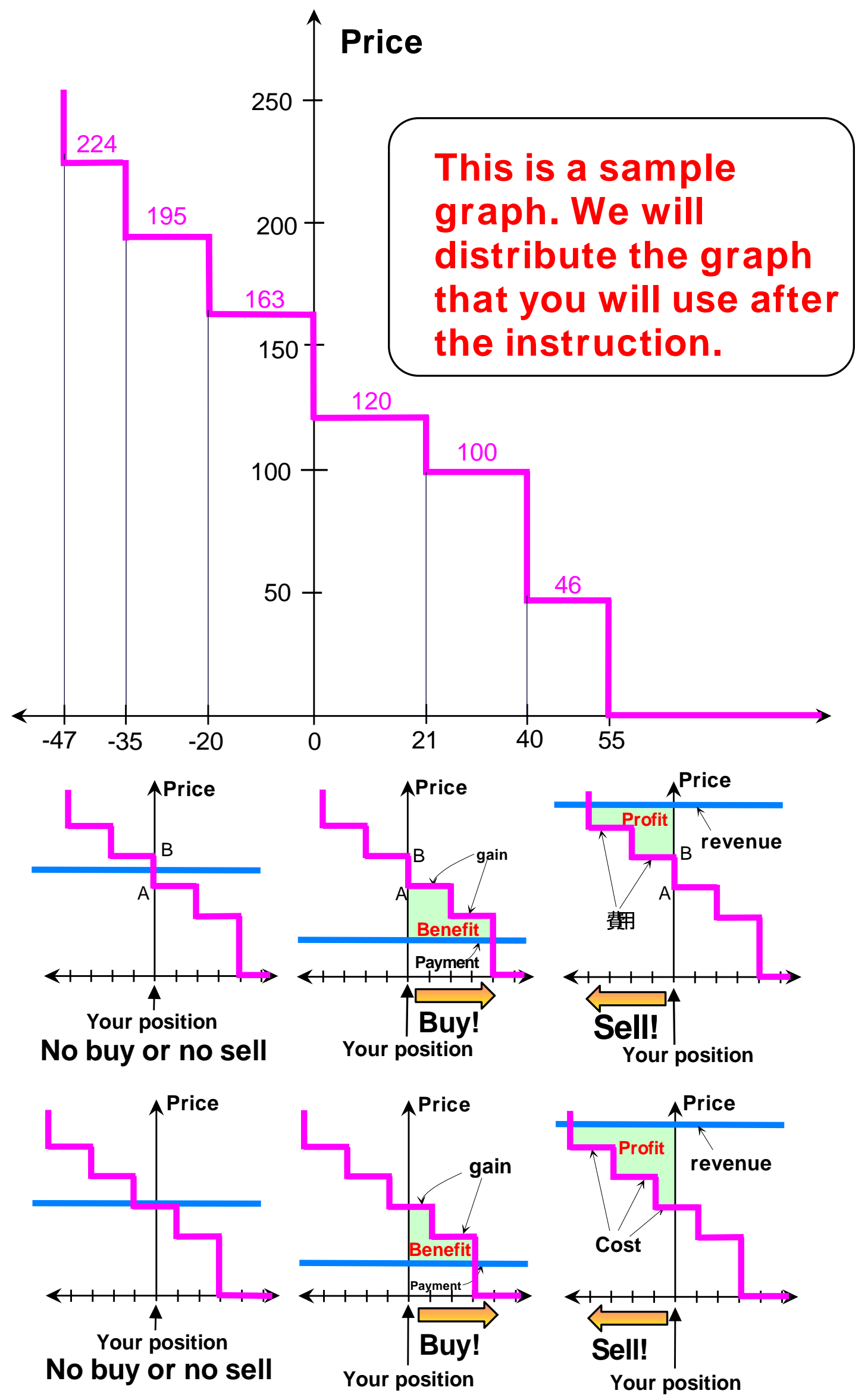

Figure 1. A Sample Graph 


\section{1-Russia 2-Ukraine 3-USA 4-Poland 5-EU 6-J apan}

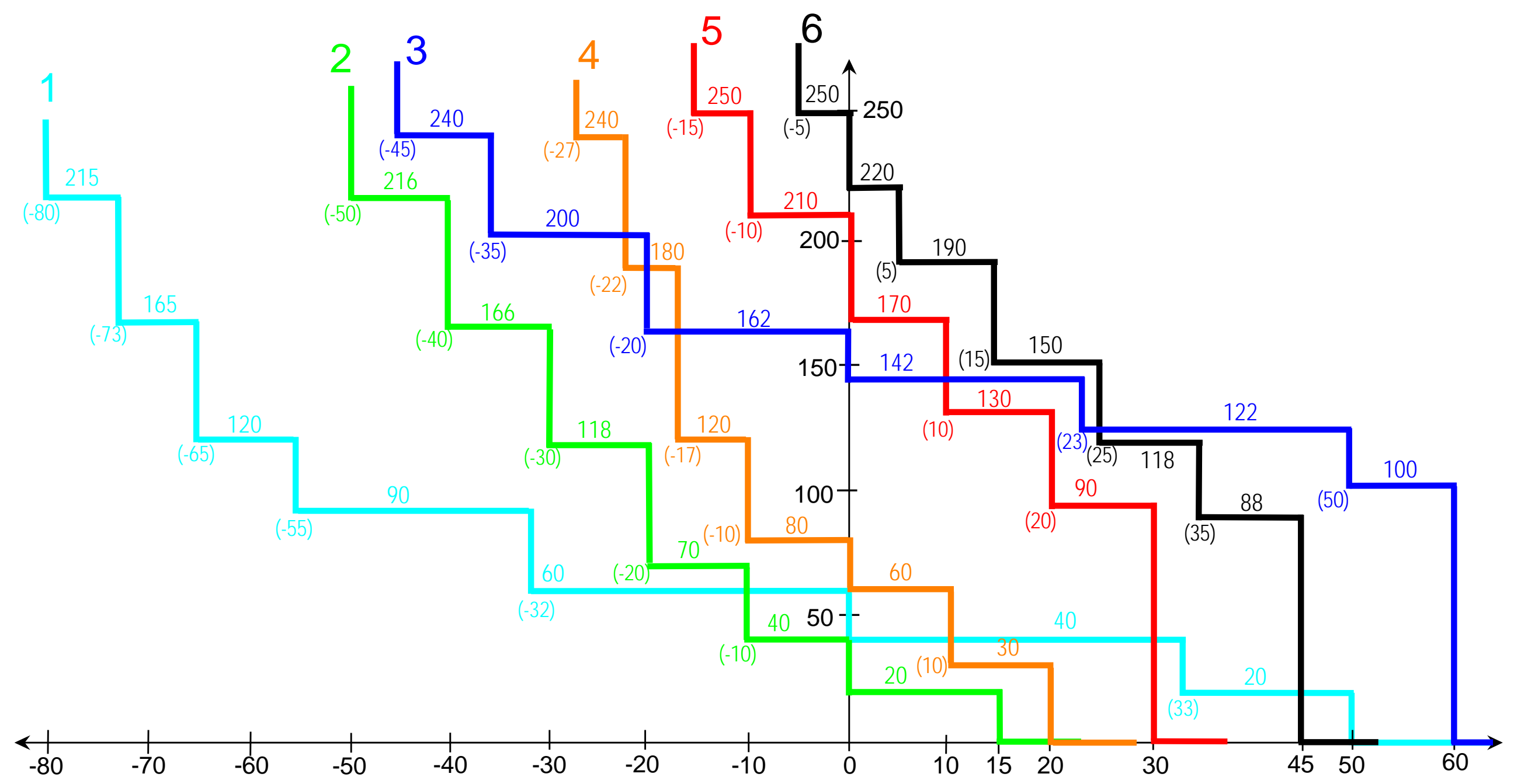

No country names were given to subjects in the experiment.

Figure 2. All Marginal Abatement Cost Curves 


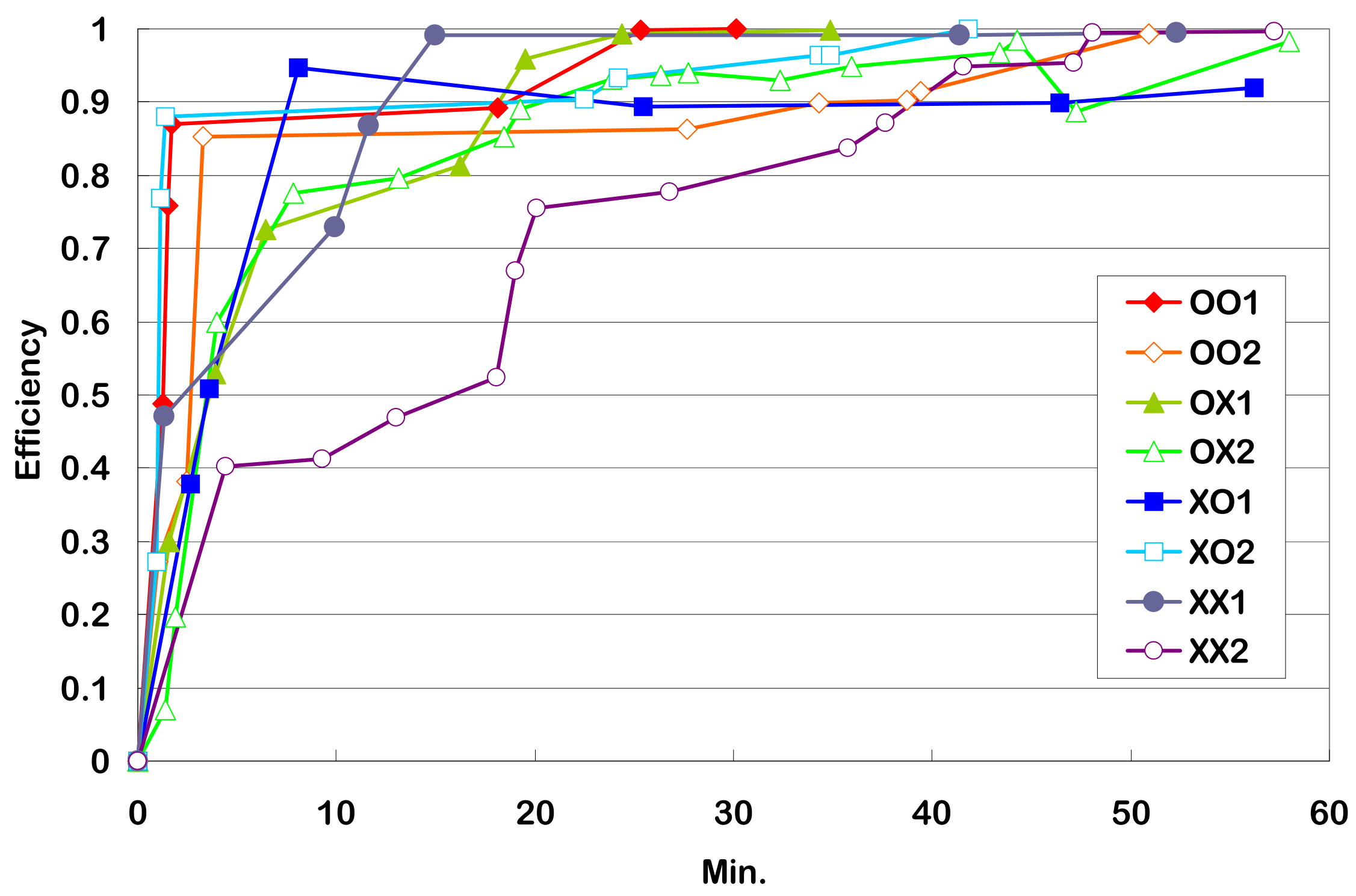

Figure $2 \frac{1}{2}$. Efficiency over Time. 

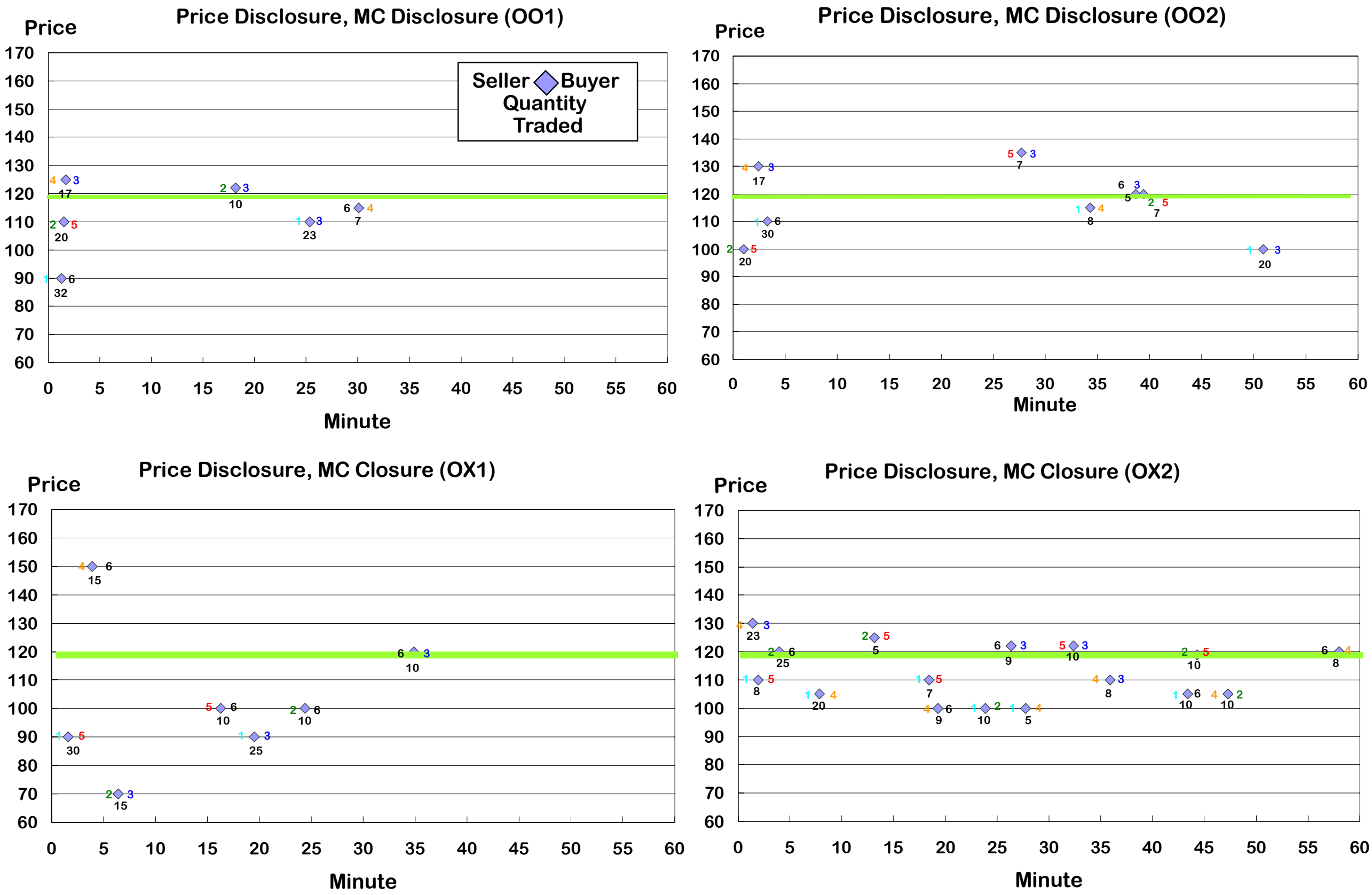

Figure 3-1. Contracted Prices and Quantities over Time. 
Price Price Closure, MC Disclosure (X01)
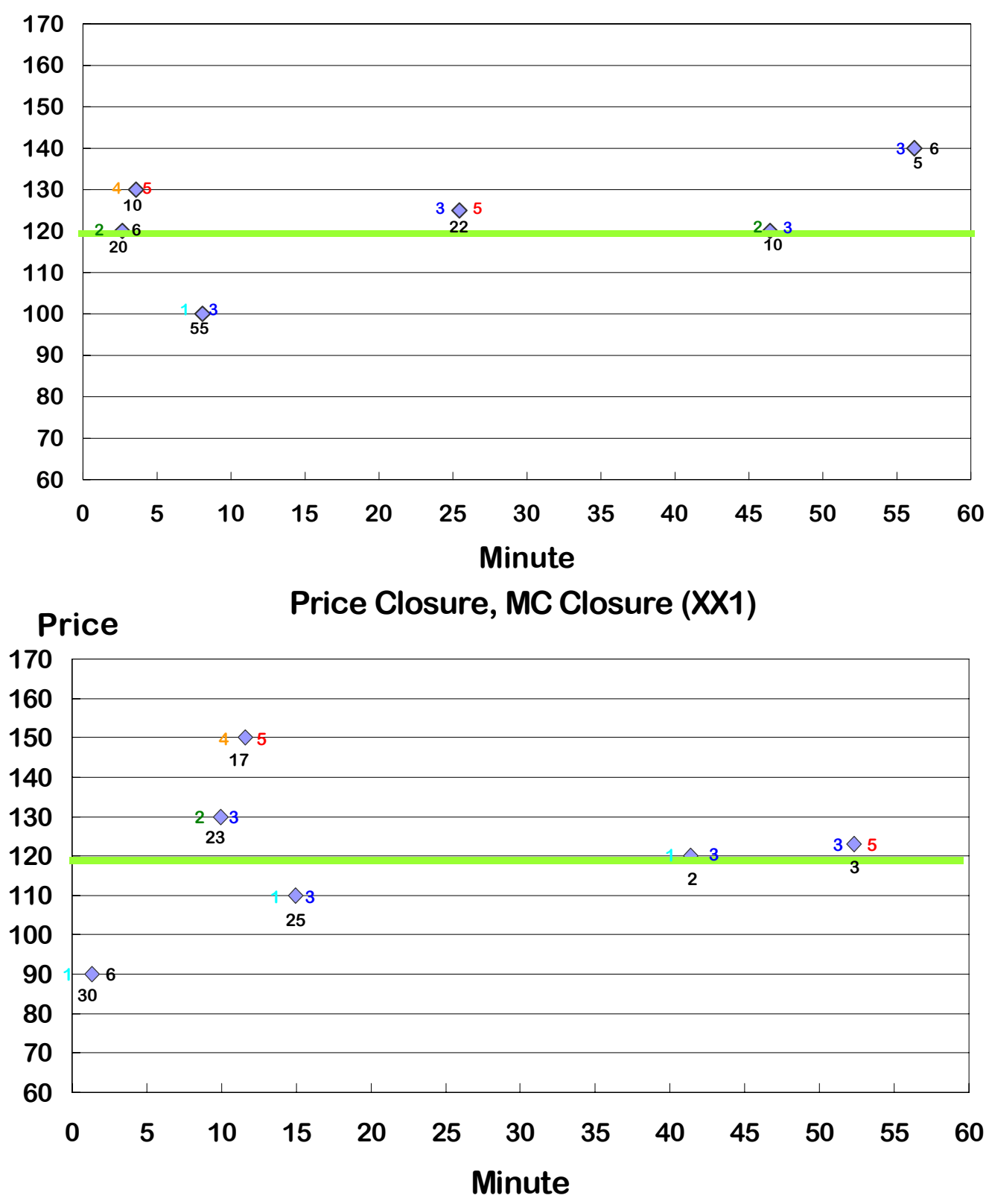

Price Price Closure, MC Disclosure (XO2)
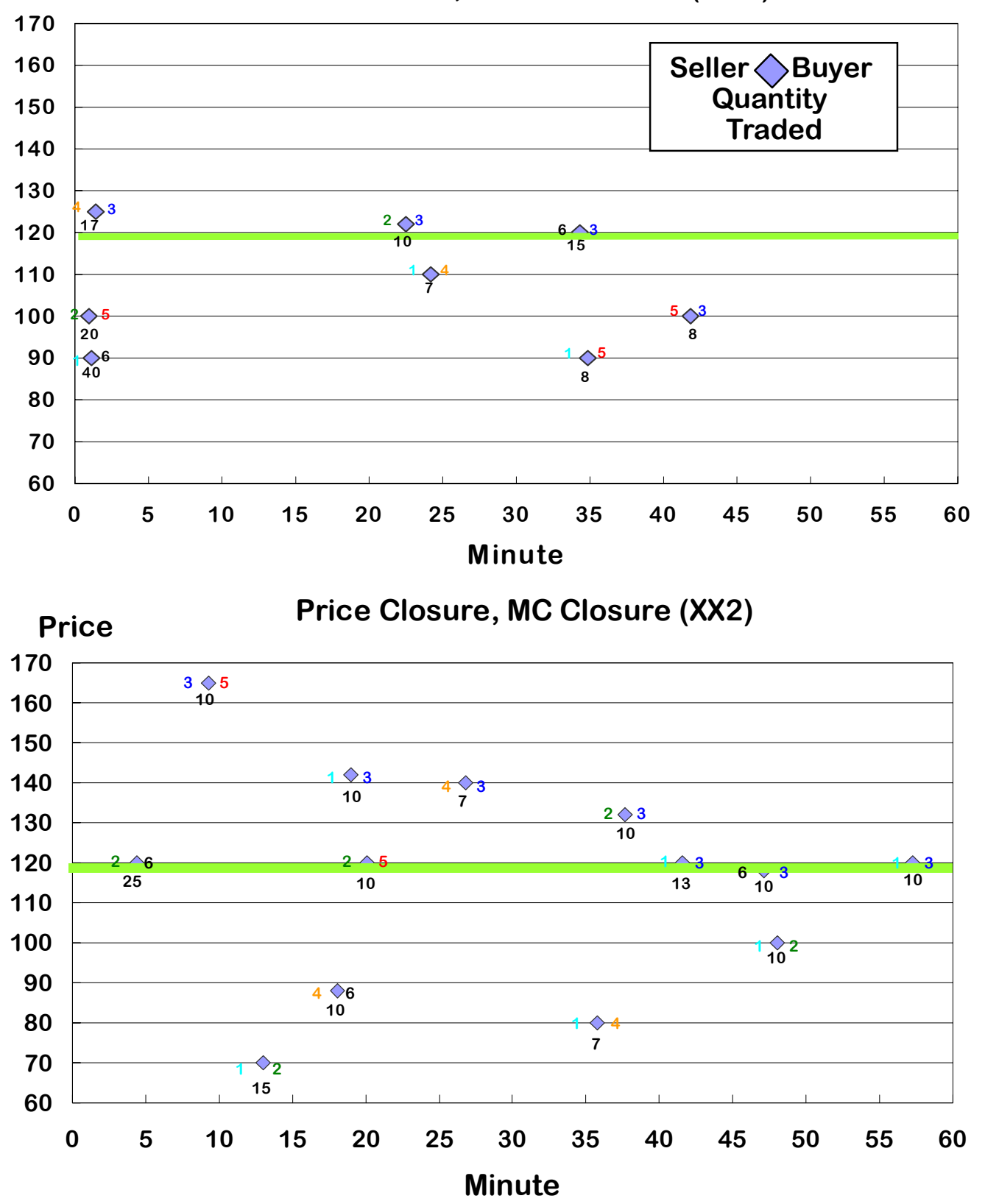

Figure 3-2. Contracted Prices and Quantities over Time. 

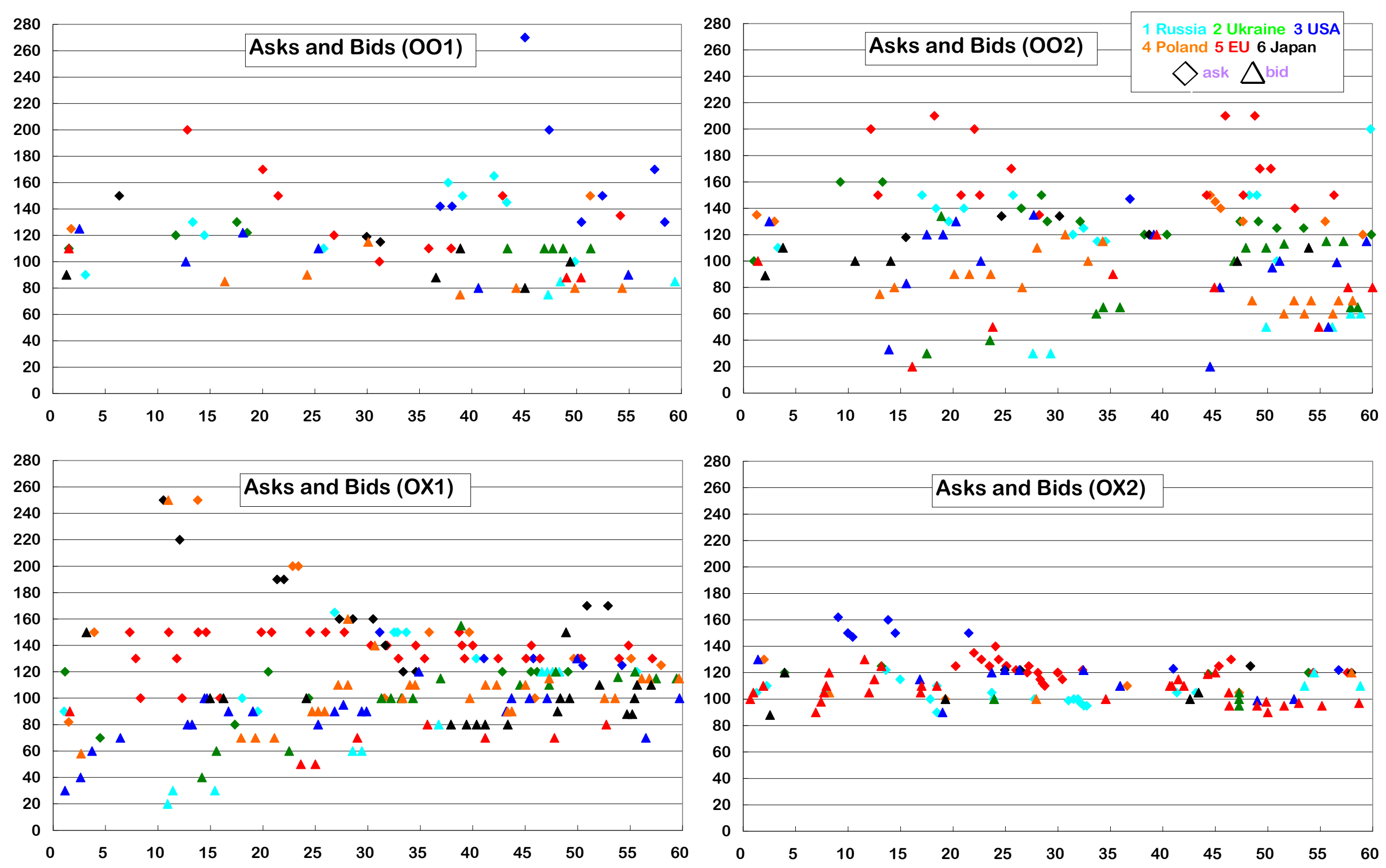

Figure 4-1.Bids and Asks over Time. 

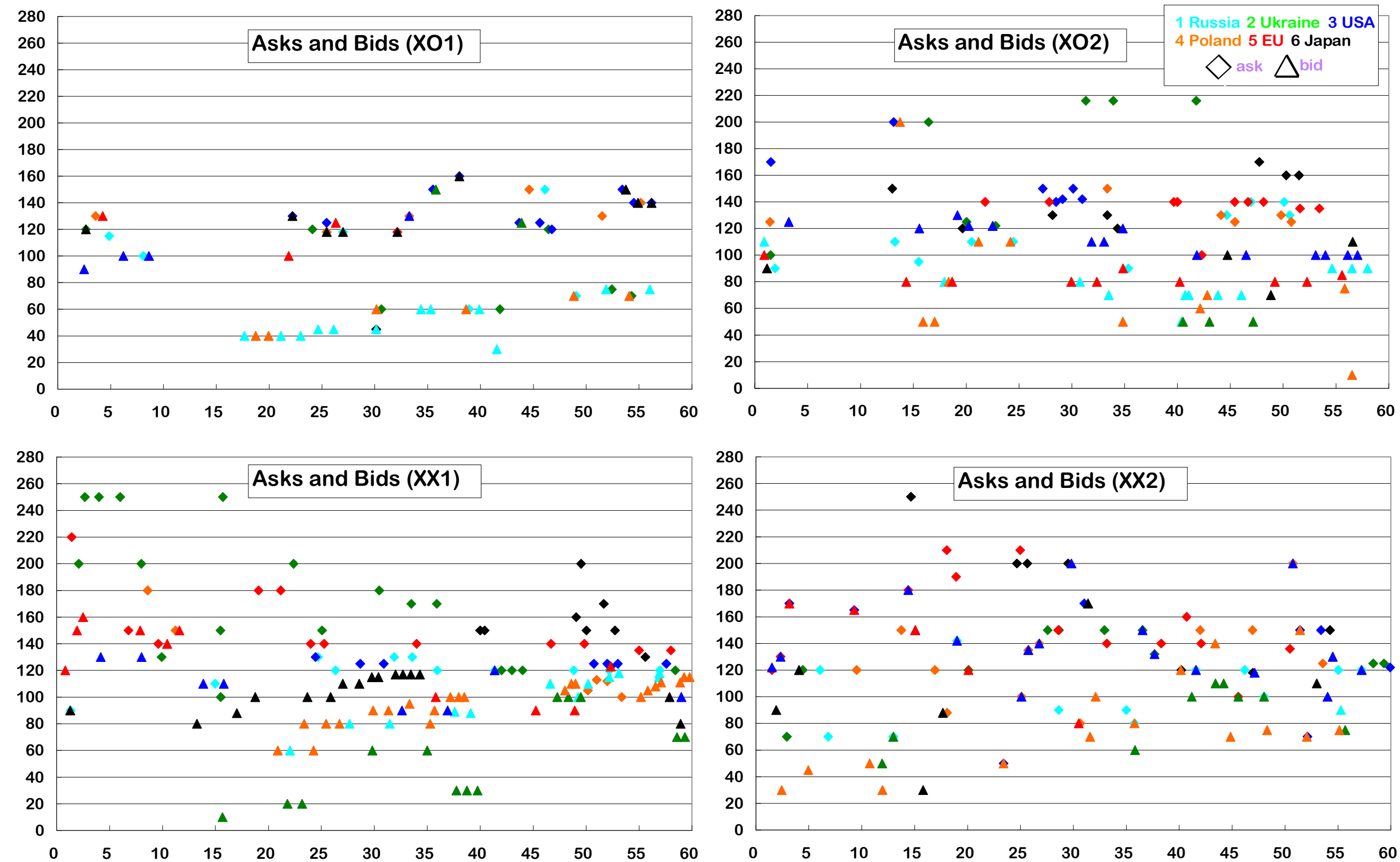

Figure 4-2. Bids and Asks over Time. 

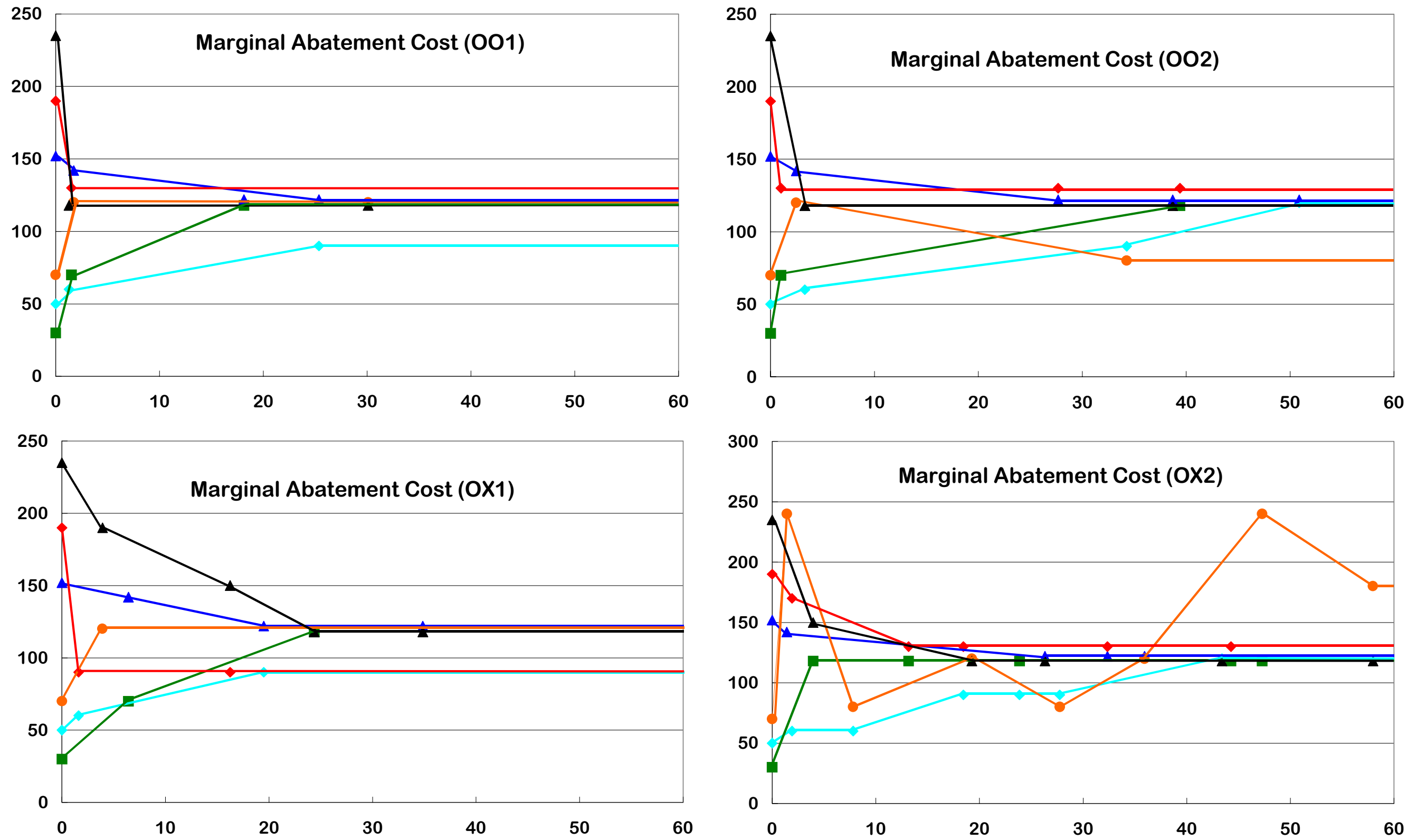

Figure 5-1. Marginal Abatement Cost over Time. 

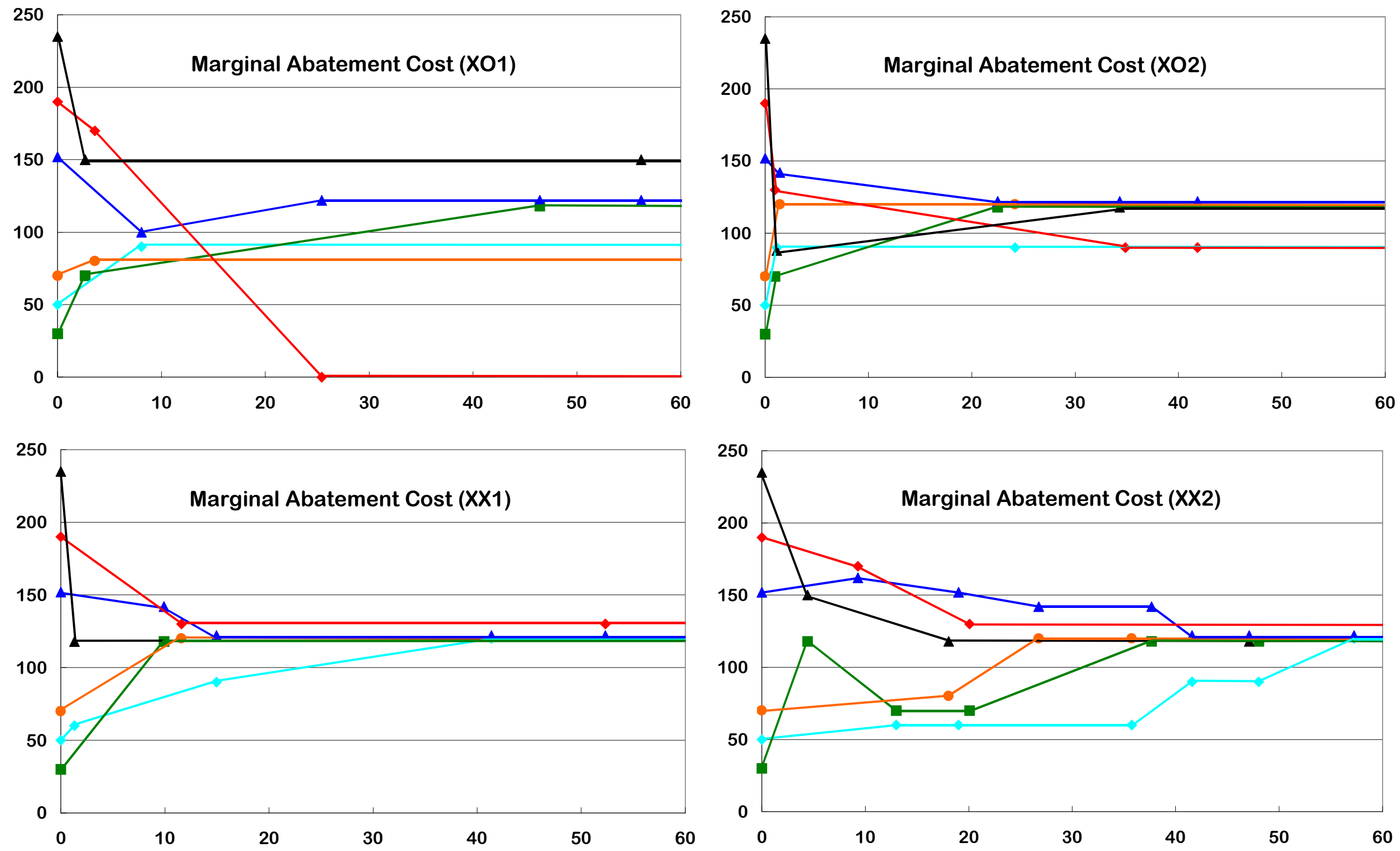

Figure 5-2. Marginal Abatement Cost over Time. 